\title{
The impact of biosimilar insulins on the diabetes landscape
}

\section{SUMMARY}

The cost of diabetes care in the United States continues to rise, with insulin costs growing rapidly. Accessibility and affordability of these life-saving medications are concerns for providers and patients that need to be addressed. Availability of biosimilar insulin products may help address these issues by introducing additional competition to the insulin market, but they may also face adoption challenges from patients and health care providers alike. In addition, policymakers at state and federal levels are examining and addressing rising insulin costs through legislative and administrative actions. The purpose of this paper is to review the current US diabetes landscape, highlight the differences between biosimilar insulins and follow-on insulins and considerations for successful adoption of biosimilar insulins, and review the current policy landscape regarding rising insulin costs.

\author{
Author affiliations \\ Jentora White, PharmD; Afton Wagner, \\ PharmD; and Hima Patel, PharmD, MBA, \\ Sandoz, Inc., Princeton, NJ \\ AUTHOR CORRESPONDENCE: \\ Jentora White, 862.926.8701; \\ jentora-1.white@novartis.com \\ J Manag Care Spec Pharm. \\ 2022;28(1):91-98 \\ Copyright $\odot 2022$, Academy of Managed \\ Care Pharmacy. All rights reserved.
}

is the cost of diabetes medications, especially insulin. ${ }^{3}$ Insulin prices have steadily increased over the years, with out-of-pocket (OOP) costs per prescription for Medicare Part D beneficiaries increasing $18 \%$, from $\$ 49$ in 2014 to $\$ 58$ in 2019, while the average annual insulin price per patient increased $55 \%$, from $\$ 3,819$ to $\$ 5,917 .^{4}$ Meanwhile, in 2018, the mean annual OOP costs for privately insured pediatric and young adult patients with T1D was \$494, with annual spending of more than $\$ 1,000$ for 1 in 8 patients. ${ }^{5}$ A survey administered to T1D and T2D patients reported cost-related insulin underuse in $25.5 \%$ of patients. ${ }^{6}$ Affordability and accessibility to insulins are concerns that need to be addressed because as costs continue to rise, patients are forced to choose between obtaining their medications or paying for other necessities, leading to worse health outcomes. ${ }^{\text {? }}$
On March 23, 2020, the US Food and Drug Administration (FDA) transitioned insulin to a streamlined regulatory framework for biologics as required by the Biologics Price Competition and Innovation Act (BPCIA). ${ }^{8}$ As a result, all approved insulins are classified as biologics and subject to biosimilar competition, which creates an easier pathway for more affordable biosimilar and market. ${ }^{8}$ The insulin market remains highly consolidated among 3 manufacturers-Eli Lilly, Novo Nordisk, and Sanofi-keeping insulin costs artificially high from a lack of robust competition. ${ }^{9}$ Of note, Novo Nordisk recently partnered with Walmart to produce the first "private-label"

\section{Follow-On and Biosimilar Insulins} interchangeable insulins to enter the
A present, ongoing barrier for patients to achieve glycemic control 


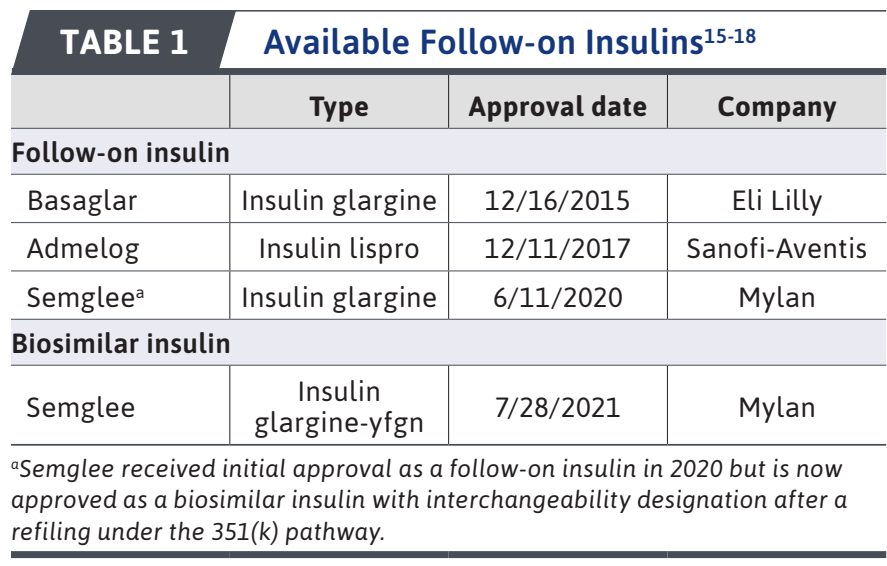

insulin at a reduced cost. ${ }^{10}$ Increased competition in the diabetes marketplace may help lower costs due to high list prices at launch ${ }^{11}$ and help support and fund innovation. Biosimilars are currently in development for aspart, lispro, and glargine insulins. ${ }^{11-14}$

There is 1 approved biosimilar insulin with an interchangeability designation to date and 2 "follow-on" insulins available (Table 1)..$^{15-18}$ Follow-on insulins are insulins approved via the Food, Drug, and Cosmetic Act section 505(b)(2), ${ }^{19,20}$ an abbreviated approval pathway used when the reference has been approved via the usual 505(b) (1) pathway. ${ }^{19}$ They are not considered biosimilars in the United States for this reason; however, they are considered biosimilars in other markets. ${ }^{19}$ In the case of Basaglar, the data to support approval included a series of clinical studies to demonstrate similarity to the reference insulin, including pharmacokinetic/pharmacodynamic studies in patients with T1D and healthy subjects and immunogenicity assessments in patients with both T1D and T2D. ${ }^{21}$ Despite availability of follow-on insulins, the insulin market remains mostly consolidated among the main manufacturers, with little competition to drive down costs.

\section{Considerations for Biosimilar Insulin Uptake}

Safety and immunogenicity are concerns for biologics, including biosimilars, but the rigorous development process required by the FDA for biosimilar approval is designed to ensure that there are no additional concerns above and beyond those already known with the reference product. Immunogenicity refers to the ability of cells or tissues to cause an undesirable immune response. ${ }^{22}$ Small changes in manufacturing processes can alter immunogenicity of biologics, such as differences in glycosylation patterns or the presence of impurities. While hypothetical, no such differences in immunogenicity have been observed to date with biosimilar use in various therapeutic areas approved in the United States or Europe. ${ }^{23,24}$ Insulins are known to be immunogenic, but the observed immunogenicity has been shown not to be clinically relevant. ${ }^{25}$

Another consideration is interchangeability, or the ability to switch from reference to biosimilar insulin without prescriber input. There is concern that switching may increase the risk of immunogenicity; however, no published data to date demonstrate this risk. ${ }^{26}$ In fact, 2 systematic reviews that evaluated all available data on the effects of switching and immunogenicity in various therapeutic areas found no clinically relevant increased risk of immunogenicity after a reference-to-biosimilar switch. ${ }^{24,27}$ The FDA addresses this issue in a draft guidance for biosimilar and interchangeable insulins, stating that there should be "no residual uncertainty regarding immunogenicity" if the analytical assessment demonstrates that the reference and biosimilar insulins are highly similar. ${ }^{28}$

Patient perceptions toward biosimilars and the potential impact on adherence are also key considerations for biosimilar insulins uptake. Negative patient perceptions and expectations can lead to the nocebo effect, in which these perceptions induce negative pharmacologic effects that are unrelated to the treatment's pharmacological action. ${ }^{29-31}$ One example is the thought that biosimilars are substandard in efficacy, safety, and quality to the reference product, similar to how some patients perceive generics as inferior to the branded counterpart. ${ }^{32}$ This negative effect can in turn decrease adherence rates and lower the patient's quality of life. ${ }^{30,31}$ Awareness of the existing clinical and real-world evidence on biosimilars is key to improving understanding and uptake of biosimilars for patients. ${ }^{30,31}$

Given the various factors and considerations for biosimilar insulin uptake, continuing education for health care professionals and patients is needed as new biosimilar insulins are approved and marketed. ${ }^{33}$

\section{Projected Cost Savings With Biosimilars}

While biologics are valuable interventions in treating numerous health conditions, they are significant contributors to health care costs. ${ }^{34}$ Insulin is no exception. Biosimilars offer a potentially lower price and equally efficacious alternative 
that may also reduce treatment costs through increased competition within the market. ${ }^{35}$ In the years since implementation of BPCIA in the United States, biosimilars across a variety of therapeutics areas have saved approximately \$37 billion compared to what spending would have been without biosimilars on the market. ${ }^{34}$ Additionally, it is estimated that biosimilars across therapeutic areas will reduce direct spending on biologics by $\$ 54$ billion from 2017 to 2026; however, actual savings will depend on regulatory and industry factors, as well as potential policy changes. ${ }^{36}$ For example, oncology budget impact models were created to assess potential cost savings across numerous areas, including OOP costs, Medicare, payers, and payments to providers. ${ }^{37,38}$ According to one model, the projected cost savings are \$123 million for Medicare, \$86 million for commercial insurers, and $\$ 47$ million for patient OOP costs over 5 years..$^{35}$ For actual cost savings, biosimilar filgrastim demonstrated a savings of \$65 to \$3,692 per patient vs the reference filgrastim and reference pegfilgrastim, a long-acting derivative of filgrastim..$^{39}$

For the insulin market specifically, both long-acting and rapid-acting insulin analogues were shown to be beneficial to diabetes patients in safely achieving glycemic control; however, the high cost of insulins becomes a barrier to access and affordability for patients with diabetes. The potential benefit of biosimilar insulin availability includes providing the same benefit-risk profile at a substantially lower cost, thus increasing affordability and accessibility to insulins. ${ }^{40}$ Available data are limited regarding the cost of biosimilar insulins in the United States; however, an analysis was recently conducted on the costs and net sales of all insulin glargine products over a period of 10 years (Q1 2010 through Q2 2020), which included the entry of the follow-on insulin Basaglar. ${ }^{41}$ Prior to the approval of Basaglar in Q4 2014, the list price per 100 IU of Lantus, the sole insulin glargine on the market, increased on average \$0.36 (4.9\%) quarterly $(\mathrm{P}<0.001)$, from $\$ 9.93$ to $\$ 22.21$, with the net price increasing at a slower rate of $3.8 \%$ quarterly. ${ }^{41}$ However, after the approval of Basaglar, net prices decreased steadily on average by $\$ 0.67$ or $5.2 \%$ per quarter $(P<0.001)$, with the weighted average net price for insulin glargine decreasing at a rate of 3.4\% quarterly. ${ }^{41}$ The availability of Basaglar was associated with a significant downward trend in net price for Lantus and the average price across insulin glargine products. ${ }^{41}$ As biosimilar insulins enter the market, more data on the impact to cost will become available.

\section{Federal Policy Landscape for Insulins}

Over the past decade, anecdotal stories from patients/ caregivers and subsequent data on the negative impact of insulin costs have captured the attention of policymakers. ${ }^{1,42-44}$ Congress' focus on the high cost of insulin is part of a larger legislative effort to lower prescription drug prices for Americans..$^{45}$ In the 116th Congress, multiple committees held hearings on insulin affordability, and members introduced legislation that both directly and indirectly addressed insulin. ${ }^{46,47}$ Proposals specific to insulin explored strategies such as lowering or eliminating OOP costs, eliminating "price gouging," and importation. ${ }^{47}$ Broader drug-pricing proposals focused on strategies such as addressing drug price inflation rates, and drug price negotiations by the federal government continue to be considered in the 117th Congress. ${ }^{47,48}$ In August 2021, House committee leaders sent letters to 3 insulin manufacturers requesting information on actions to lower insulins costs, following up on similar letters sent in 2019 prior to the insulin affordability hearings. ${ }^{49}$ The high cost of insulin continues to be a key issue in larger drug-pricing conversations and could potentially drive reintroduction of legislation or new proposals in the 117th Congress.

The Trump administration issued several executive orders (EOs) intended to lower the cost of prescription drugs, including insulin, in the United States; however, none have been implemented. ${ }^{50-56}$ Drug pricing continues to be a key issue for the Biden administration, which may lead to policies being developed that either directly or indirectly affect insulins. For example, a broad EO titled "Promoting Competition in the American Economy" addressed the prescription drug market and directed the US Department of Health and Human Services to submit a report on specific actions to address the high cost of prescription drugs. ${ }^{57}$ Additionally, President Biden addressed prescription drug costs in an August 2021 statement, urging Congress to implement reforms that would lower the cost of prescription drugs, specifically mentioning insulins. ${ }^{58}$ While it is clear that drug pricing and affordability remain a concern for patients and a priority for the 117th Congress and the Biden administration, it remains to be seen if any new drug-pricing legislation or policies will move forward and how those would affect insulins. 


\section{Insulins in the Medicare Program}

Diabetes affects approximately 1 in 3 seniors enrolled in Medicare, a population more likely to experience diabetesrelated complications. ${ }^{59,60}$ As a result, policy makers are interested in addressing the high cost of insulin in this program. Medicare beneficiaries receive coverage of insulin through Medicare Part B and Part D. Part B covers insulin pumps and related products while Part D covers outpatient insulin products and supplies such as syringes. ${ }^{61}$ Part D beneficiaries are subject to a coinsurance or copayment for insulin products, triggering the development of policies that seek to cap or eliminate OOP costs. ${ }^{61}$

Between 2007 and 2017, total Part D spending on insulin increased over $800 \%$, from $\$ 1.4$ billion to $\$ 13.3$ billion. ${ }^{62}$ During a similar time frame, OOP spending for insulin products in Part D grew from $\$ 236$ million to $\$ 968$ million. ${ }^{62}$ To address this issue in the Part D program, the Centers for Medicare \& Medicaid Services (CMS) announced a new Part D Senior Savings Model that commenced on January $1,2021 .{ }^{63}$ At least 88 insurers representing 1,750 Medicare Advantage and Part D prescription drug plans opted to participate in the voluntary model that allows participants to cap OOP insulin costs for beneficiaries at $\$ 35$ for a 30 -day supply during the 2021 plan year. ${ }^{64}$ CMS estimates that Medicare beneficiaries who enroll in a participating model should save an average of \$446 in annual OOP costs on insulin..$^{59}$

\section{State Policy Landscape for Insulins}

The rising cost of insulin has also captured the attention of policymakers at the state level. In 2017, Nevada passed a law that deemed all forms of insulin as essential medicines and would require insulin manufacturers and pharmacy benefit managers (PBMs) to annually report certain data points to the state regarding insulin expenditures. ${ }^{65} \mathrm{~A}$ number of states have enacted laws to address concerns voiced by constituents and advocacy groups about the cost of insulin and the impact on access. ${ }^{66}$ To assist states in addressing insulin costs, the Diabetes Patient Advocacy Coalition and the National Diabetes Volunteer Leadership Council drafted legislative framework in 2018 that included prescription drug cost transparency language. ${ }^{67}$

In 2019, Colorado passed legislation to cap the OOP cost for insulin to no more than $\$ 100$ a month for a 30-day supply. ${ }^{68}$ Since then, at least 17 other states followed suit and passed laws that enacted OOP caps on insulin. ${ }^{69}$ Most of these laws have taken effect, and OOP monthly caps range from $\$ 25$ to $\$ 100 .{ }^{66}$ Additional states introduced OOP cap legislation that either died in committee or was not considered. ${ }^{66}$

\section{Private Insurer Policy Landscape for Insulins}

In addition to federal and state policy proposals, private insurers are also addressing the high cost of insulin by offering copay caps or programs that lower or eliminate OOP costs. New York-based Oscar Health caps some plan members' OOP costs for insulin and other medications at $\$ 3.00$ for a month's supply. ${ }^{70}$ Cigna and its PBM Express Scripts allow employers the option to offer members a 30-day supply of insulin for \$2 through its Patient Assurance Program. ${ }^{71}$ CVS Health implemented its RxZERO program to eliminate OOP costs for all prescription diabetes medications for members whose pharmacy benefits are managed by the company's PBM. $^{72}$ Additionally, Medica implemented an insulin cost relief program that caps a 30-day supply of insulin at a \$25 copayment for fully insured employer groups in 4 states. $^{73}$

\section{Conclusions}

The rising cost of prescription medications continues to be a challenge for patients, caregivers, health care providers, payers, and policy makers. On federal and state levels, policy makers are focused on access to and affordability of insulin. Numerous policies have been proposed and will continue to be pursued in 2021. With the prevalence rate of diabetes expected to increase in the United States, biosimilar insulins can promote competition, potentially decreasing both drug and health care costs and increasing patient access. ${ }^{36}$ In terms of costs, $\$ 37$ billion has been saved after implementation of the BPCIA compared to what spending would be without biosimilars, ${ }^{34}$ and it is estimated that biosimilars will provide $\$ 54$ billion in savings in direct spending on biologic medicines from 2017 to $2026 .{ }^{36}$ This competition and savings help support innovative advances in an evolving diabetes landscape.

Although additional biosimilar insulins will soon be available in the United States, potential barriers to uptake remain, such as negative perceptions toward biosimilars and generics, safety/immunogenicity concerns, and interchangeability with existing insulins. Awareness of these challenges and addressing considerations for biosimilar insulin uptake and negative perceptions through education are key to ensure patients and health care professionals alike are comfortable with biosimilar insulins. 


\section{DISCLOSURES}

This Viewpoints article was supported by Sandoz, Inc. Wagner and Patel are employees of Sandoz, Inc. White was employed by Sandoz, Inc., at the time of this study.

\section{REFERENCES}

1. Centers for Disease Control and Prevention. National diabetes statistics report 2020: estimates of diabetes and its burden in the United States. 2020. Accessed October 19, 2020. https://www. cdc.gov/diabetes/pdfs/data/statistics/ national-diabetes-statistics-report.pdf

2. Rowley WR, Bezold C, Arikan Y, Byrne E, Krohe S. Diabetes 2030: insights from yesterday, today, and future trends. Popul Health Manag. 2017;20(1):6-12.

3. Riddle MC, Bakris G, Blonde L, et al. Professional practice committee: standards of medical care in diabetes -2020 . Diabetes Care. 2020;43(Suppl 1):S1-S212.

4. Tseng CW, Masuda C, Chen R, Hartung DM. Impact of higher insulin process on out-of-pocket costs in Medicare Part D. Diabetes Care. 2020;43:e50-e51.

5. Chua KP, Lee JM, Conti RM. Potential change in insulin out-of-pocket spending under cost-sharing caps among pediatric patients with type 1 diabetes. JAMA Pediatrics. 2021;175(1):90-92.

6. Herkert D, Vijayakumar P, Luo J, et al. Cost-related insulin underuse among patients with diabetes. JAMA Intern Med. 2019;179(1):112-14.

7. Cefalu WT, Dawes DE, Gavlak G, et al.; Insulin Access and Affordability Working Group. Insulin Access and Affordability Working Group: conclusions and recommendations. Diabetes Care. 2018;41:1299-311.

8. US Food and Drug Administration. Insulin gains new pathway to increased competition. March 23, 2020. Accessed October 21, 2020. https://www.fda.gov/ news-events/press-announcements/ insulin-gains-new-pathway-increasedcompetition
9. Pharmaceutical Care Management Association. Insulins: managing costs with increasing manufacturer prices. August 2020. Accessed October 22, 2020. https://www.pcmanet.org/wp-content/ uploads/2020/08/PCMA_VisanteInsulins-Prices-and-Costs-.pdf

10. Walmart. Walmart revolutionizes insulin access \& affordability for patients with diabetes with the launch of the first and only private brand analog insulin. June 29, 2021. Accessed August 30, 2021. https://corporate. walmart.com/newsroom/2021/06/29/ walmart-revolutionizes-insulin-accessaffordability-for-patients-with-diabeteswith-the-launch-of-the-first-and-onlyprivate-brand-analog-insulin

11. Celltrion. Celltrion-Poonglim Pharmatech selected 'national no. 1' insulin pen-type injection drug as a national project. June 3, 2020. Accessed March 10, 2021. https:// pharmashots.com/press-releases/ celltrion-poonglim-pharmatech-selectednational-no-1insulin-pen-type-injectiondrug-as-a-national-project/

12. Lannett. Lannett development of biosimilar insulin glargine product continues to advance. March 10, 2021. Accessed April 20, 2021. https://lannett.investorroom. com/2021-03-10-Lannett-DevelopmentOf-Biosimilar-Insulin-Glargine-ProductContinues-To-Advance

13. Sandoz. Sandoz enters into commercialization and supply agreement for insulin biosimilars, anticipating growing demand as diabetes burden rises. December 19, 2018. Accessed March 10, 2021. https://www.sandoz.com/news/media-releases/ sandoz-enters-commercialization-andsupply-agreement-insulin-biosimilars.

14. Generics and Biosimilars Initiative. US biosimilars pipeline for immunosuppressants, insulin and ophthalmology - 2021. May 21, 2021. Accessed October 21, 2021. https://gabionline.net/reports/us-biosimilars-pipeline-for-immunosuppressants-insulin-and-ophthalmology-2021
15. US Food and Drug Administration. Drugs@FDA. Basaglar FDA approval. Accessed October 28, 2020. https:// www.accessdata.fda.gov/scripts/ cder/daf/index.cfm?event=overview. process\&ApplNo $=205692 \mathrm{~A}$

16. US Food and Drug Administration. Drugs@FDA. Admelog FDA approval. Accessed October 28, 2020. https:// www.accessdata.fda.gov/scripts/ cder/daf/index.cfm?event=overview. process\&ApplNo $=209196$

17. US Food and Drug Administration. Drugs@FDA. Semglee FDA approval. Accessed October 28, 2020. https:// www.accessdata.fda.gov/scripts/ cder/daf/index.cfm?event=overview. process \&ApplNo $=210605$

18. US Food and Drug Administration. Drugs@FDA. Semglee FDA approval. Accessed August 30, 2021. https:// www.accessdata.fda.gov/scripts/ cder/daf/index.cfm?event=overview. process\&ApplNo $=761201$

19. Davies M, Dahl D, Heise T, Mathieu C. Introduction of biosimilar insulins in Europe. Diabet Med. 2017;34(10):1340-53.

20. US Food and Drug Administration. FDA approves Basaglar, the first 'follow-on' insulin glargine product to treat diabetes. December 16, 2015. Accessed October 28, 2020. http://www.fda.gov/NewsEvents/ Newsroom/PressAnnouncements/ ucm477734.htm

21. White J, Goldman J. Biosimilar and follow-on insulin: the ins, outs, and interchangeability. J Pharm Technol. 2019;35(1):25-35.

22. Pineda C, Castañeda Hernández G, Jacobs IA, Alvarez DF, Carini C. Assessing the immunogenicity of biopharmaceuticals. BioDrugs. 2016;30(3):195-206.

23. Barbier L, Ebbers HC, Declerck P, Simoens S, Vulto AG, Huys I. The efficacy, safety, and immunogenicity of switching between reference biopharmaceuticals and biosimilars: a systematic review. Clin Pharmacol Ther. 2020;108(4):734-55. 
24. Cohen HP, Blauvelt A, Rifkin RM, Danese S, Gokhale SB, Woollett G. Switching reference medicines to biosimilars: a systematic literature review of clinical outcomes. Drugs. 2018;78:463-78.

25. Fineberg SE, Kawabata TT, Finco-Kent D, Fountaine RJ, Finch GL, Krasner AS. Immunological responses to exogenous insulin. Endocrine Rev. 2007;28(6):625-52.

26. Ebbers HC, Schellekens H. Are we ready to close the discussion on the interchangeability of biosimilars? Drug Dis Today. 2019;24(10):1963-67.

27. McKinnon RA, Cook M, Liauw W, et al. Biosimilarity and interchangeability: principles and evidence: a systematic review. BioDrugs. 2018;32(1):27-52.

28. US Food and Drug Administration. Considerations in demonstrating interchangeability with a reference product. Guidance for industry. Accessed October 28, 2020. https://www.fda.gov/ media/124907/download

29. Pouillon L, Socha M, Demore B, et al. The nocebo effect: a clinical challenge in the era of biosimilars. Expert Rev Clin Immunol. 2018;14(9):739-49.

30. Rezk MF, Pieper B. Treatment outcomes with biosimilars: be aware of the nocebo effect. Rheumatol Ther. 2017;4(2):209-18.

31. Rezk MF, Pieper B. To see or NOsee: the debate on the nocebo effect and optimizing the use of biosimilars. Adv Ther. 2018;35(6):749-53.

32. Haükonsen H, Eilertsen M, Borge H, Toverud E. Generic substitution: an additional challenge for adherence in hypertensive patients? Curr Med Res Opin. 2009;25(10):2515-21.

33. Zhang RM, Puri R, McGill JB. Update on biosimilar insulins: a US perspective. BioDrugs. 2020;34(4):505-12.

34. IQVIA Institute. Biosimilars in the United States 2020-2024: competition, savings, and sustainability. 2020. Accessed March 26, 2021. https://www.iqvia.com/ insights/the-iqvia-institute/reports/biosimilars-in-the-united-states-2020-2024
35. Grewal S, Ramsey S, Balu S, Carlson JJ. Cost-savings for biosimilars in the United States: a theoretical framework and budget impact case study application using filgrastim. Expert Rev Pharmacoecon Outcomes Res. 2018;18(4):447-54.

36. Mulcahy A, Hlavka JP, Case SR. Biosimilar cost savings in the United States: initial experience and future potential. Rand Health Q. 2018;7(4):3.

37. McBride A, Balu S, Campbell K, Bikkina M, MacDonald K, Abraham I. Expanded access to cancer treatments from conversion to neutropenia prophylaxis with biosimilar filgrastim-sndz. Future Oncol. 2017;13(20):2285-95.

38. Puckrein G, Xu L, Ryan A, Campbell K, Balu S. Potential Medicare beneficiary out-of-pocket reductions through using biosimilar filgrastim-sndz over reference filgrastim: a simulation analysis. J Manag Care Spec Pharm. 2018;24 (10-a Suppl):S100. doi:10.18553/jmcp.2018. 24.10-a.s1

39. McBride A, Campbell K, Bikkina M, MacDonald K, Abraham I, Balu S. Cost-efficiency analyses for the US of biosimilar filgrastim-sndz, reference filgrastim, pegfilgrastim, and pegfilgrastim with on-body injector in the prophylaxis of chemotherapy-induced (febrile) neutropenia. J Med Econ. 2017;20(10):1083-93.

40. Edelman S, Polonsky WH, Parkin CG. Biosimilar insulins are coming: what are they, what you need to know. Curr Med Res Opin. 2014;30(11):2217-22.

41. Levy J, Chowdhury ZM, Socal MP, et al. Changes associated with the entry of a biosimilar in the insulin glargine market. JAMA Intern Med. Published online June 28, 2021. doi:10.1001/ jamainternmed.2021.2769

42. National Coalition on Health Care. Policy solutions to address the rising cost of insulin. March 2019. Accessed October 21, 2020. https://nchc.org/ policy-solutions-to-address-the-risingcost-of-insulin/
43. Caffrey M. Gathering evidence on insulin rationing: answers and future questions. American Journal of Managed Care. September 16, 2019. Accessed October 19, 2020. https://www.ajmc.com/ view/gathering-evidence-on-insulinrationing-answers-and-future-questions

44. Rosenthal E. When high prices mean needless death. JAMA Intern Med. 2019;179(1):114-15

45. U.S. House of Representatives. Energy and Commerce Committee. For The People: H.R.3, The Lower Drug Costs Now Act. Accessed October 20, 2020. https://energycommerce.house.gov/ sites/democrats.energycommerce.house. gov/files/documents/H.R.\%203\%20 Summary\%20with\%20Investments\%20 in\%20Medicare\%20\%26\%20Public\%20 Health.pdf

46. Weixel N. Insulin manufacturers to testify as part of House pricing probe. April 2, 2019. Accessed October 20, 2020. https://thehill.com/policy/ healthcare/437011-insulin-manufacturersto-testify-as-part-of-house-pricing-probe

47. Cubanski J, Neuman T, True S. Insulin costs and coverage in Medicare Part D Accessed October 21, 2020. https:// www.kff.org/medicare/issue-brief/ insulin-costs-and-coverage-in-medicare-part-d/\#: :text=Formulary\%20 Coverage\%20and\%20Tier\%20Placement \%20of\%20Insulin\%20Therapies\&text= In\%202019\%2C\%20most\%20insulin\%20 products,drug\%20plans\%20(Table\%202)

48. U.S. House. 117th Congress (2021). H.R. 3. Accessed August 27, 2021. https:// www.congress.gov/bill/117th-congress/ house-bill/3/text

49. U.S. House Committee on Energy \& Commerce. E\&C leaders follow up with pharmaceutical manufacturers on the high cost of insulin. August 19, 2021. Accessed August 26, 2021. https://energycommerce.house. gov/newsroom/press-releases/ ec-leaders-follow-up-with-pharmaceutical-manufacturers-on-the-high-cost-of 
50. U.S. Department of Health and Human Services. Trump Administration announces historic action to lower drug prices for Americans. July 24, 2020. Accessed February 19, 2021. https:// www.hhs.gov/about/news/2020/07/24/ trump-administration-announces-historic-action-lower-drug-prices-americans.html

51. The White House. Executive order on access to affordable life-savings medications. July 24, 2020. Accessed October 20, 2020. https://www. whitehouse.gov/presidential-actions/ executive-order-access-affordable-lifesaving-medications/

52. The White House. Executive order on increasing drug importation to lower prices for American patients. July 24, 2020. Accessed October 20, 2020. https://www.whitehouse.gov/ presidential-actions/executive-orderincreasing-drug-importation-lowerprices-american-patients/

53. Implementation of executive order on access to affordable life-saving medications; delay of effective date. Fed Reg. 2021;86(46):13872. Accessed March 17, 2021. https://www.govinfo.gov/content/ pkg/FR-2021-03-11/pdf/2021-05165.pdf

54. US Food and Drug Administration. FDA takes actions to help lower U.S. prescription drug prices. September 24, 2020. Accessed October 20, 2020. https://www.fda.gov/news-events/ press-announcements/fda-takesactions-help-lower-us-prescriptiondrug-prices?utm_medium=email\&utm _ source $=$ govdelivery

55. Sandburg B. PhRMA sues to block HHS drug importation rule citing security, safety, first amendment concerns. The Pink Sheet. November 24, 2020. Accessed February 8, 2021. https://pink.pharmaintelligence.informa.com/PS143348/ PhRMA-Sues-To-Block-HHS-DrugImportation-Rule-Citing-Security-SafetyFirst-Amendment-Concerns
56. Proposed rescission of executive order 13937, "executive order on access to affordable life-savings medications." Fed Reg. 2021;86(114):32008. Accessed August 26, 2021. https://www.federalregister. gov/documents/2021/06/16/2021-12545/ proposed-rescission-of-executive-order13937-executive-order-on-access-toaffordable-life-saving

57. The White House. Executive order on promoting competition in the American economy. July 9, 2021. Accessed August 26, 2021. https:// www.whitehouse.gov/briefing-room/ presidential-actions/2021/07/09/ executive-order-on-promoting-competition-in-the-american-economy/

58. The White House. Fact sheet: President Biden calls on Congress to lower prescription drug prices. August 12, 2021. Accessed August 26, 2021. https:// www.whitehouse.gov/briefing-room/ statements-releases/2021/08/12/ fact-sheet-president-biden-calls-on-congress-to-lower-prescription-drug-prices/

59. Centers for Medicare \& Medicaid Services. Part D Senior Savings Model. March 11, 2020. Accessed October 20, 2020. https://www.cms.gov/newsroom/ fact-sheets/part-d-senior-savings-model

60. Kirkman MS, Briscoe VJ, Clark N, et al. Diabetes in older adults. Diabetes Care. 2012;35(12):2650-64.

61. Hasche J, Ward C, Schluterman N. Diabetes occurrence, costs, and access to care among Medicare beneficiaries aged 65 years and over. September 2017. Accessed October 20, 2020. https://www. cms.gov/Research-Statistics-Data-andSystems/Research/MCBS/Downloads/ Diabetes_DataBrief_2017.pdf

62. Cubanski J, Neuman T. How much does Medicare spend on insulin. Kaiser Family Foundation. April 1, 2019. Accessed October 20, 2020. https://www.kff.org/ medicare/issue-brief/how-much-doesmedicare-spend-on-insulin/
63. Centers for Medicare \& Medicaid Services. CMS launches groundbreaking model to lower out of pocket expenses for insulin. March 11, 2020. Accessed October 20, 2020. https://www. cms.gov/newsroom/press-releases/ cms-launches-groundbreaking-modellower-out-pocket-expenses-insulin

64. Inserro A, Caffrey M. Seniors in certain Part D plans, Medicare Advantage to see insulin costs capped in 2021. AJMC. May 26, 2020. Accessed October 20, 2020. https://www.ajmc.com/view/ seniors-in-certain-part-d-plans-medicare-advantage-to-see-insulin-costscapped-in-2021.

65. Nevada Legislature. S.B. 539. 2017 Leg., 79th Reg. Sess. (Nev. 2017). Introduced May 16, 2017. Accessed October 20, 2020. https://www.leg.state.nv.us/App/NELIS/ REL/79th2017/Bill/5822/Overview

66. Ault A. More states cap insulin cost, but activists will "fight harder". Medscape. September 3, 2020. Accessed October 22, 2020. https://www.medscape.com/ viewarticle/936825

67. Access to Lifesaving Medicines Act (ALMA). Bill summary. National Diabetes Volunteer Leadership Council and Diabetes Patient Advocacy Coalition. Accessed October 22, 2020. https://diabetespac.org/wp-content/ uploads/2018/12/Access-to-LifesavingMedicines-Act.pdf

68. CaseText. C.R.S. 10-16-151. Assemb. Reg. Sess. 2019. (Col. 2019). Introduced August 2, 2019. Accessed October 20, 2020. https://casetext.com/statute/colorado-revised-statutes/title-10-insurance/ health-care-coverage/article-16-healthcare-coverage/part-1-general-provisions/ section-10-16-151-cost-sharing-in-prescription-insulin-drugs-limits-definitionrules

69. National Council for State Legislatures. Diabetes state mandates and insulin copayment caps. July 28, 2021. Accessed August 31, 2021. https:// www.ncsl.org/research/health/ diabetes-health-coverage-state-lawsand-programs.aspx 
70. Morse S. Oscar Health offers $\$ 3$ a month drug prescriptions. February 20, 2020. Accessed October 22, 2020. https:// www.healthcarefinancenews.com/news/ oscar-health-offers-3-month-drug-prescriptions

71. Cigna. Cigna and Express Scripts introduce patient assurance program to cap out of pocket costs at \$25 per 30 -day insulin prescription. April 3, 2019. Accessed October 22, 2020. https://www.cigna.com/newsroom/ news-releases/2019/cigna-and-expressscripts-introduce-patient-assuranceprogram-to-cap-out-of-pocket-costs-at25-per-30-day-insulin-prescription
72. CVS Health. CVS Health RxZERO solution eliminates member out-ofpocket costs for diabetes medications. January 29, 2020. Accessed October 22, 2020. https://cvshealth.com/ news-and-insights/press-releases/ cvs-health-rxzero-solution-eliminatesmember-out-of-pocket-costs
73. Medica. Medica introduces insulin cost relief program. August 16, 2019. Accessed October 22, 2020. https://www.medica.com/newsroom/ press-releases/2019/08162019-medicaintroduces-insulin-cost-relief-program 